\title{
Lung deposition of budesonide inhaled via Turbuhaler®: a comparison with terbutaline sulphate in normal subjects
}

\author{
L. Borgström*, E. Bondesson*, F. Morén**, E. Trofast*, S.P. Newman+
}

Lung deposition of budesonide inhaled via Turbuhaler ${ }^{\circledR}:$ a comparison with terbutaline sulphate. L. Borgström, E. Bondesson, F. Morén, E. Trofast, S.P. Newman. CERS Journals Ltd 1994.

ABSTRACT: We wanted to evaluate whether lung deposition of budesonide and terbutaline sulphate differs, and to determine lung deposition of budesonide inhaled at different peak inspiratory flows, through Turbuhaler®.

Lung deposition of budesonide, a lipophilic substance, and of terbutaline sulphate, a hydrophilic substance, was therefore compared, after administration via an inspiratory flow-driven, multi-dose, powder inhaler (Turbuhaler ${ }^{\circledR}$, Astra Draco AB) to 10 healthy volunteers. The radionuclide ${ }^{99 m}$ Tc was used to label drug particles, and radioactivity, indicating drug deposition, was measured using a gamma camera. Budesonide was inhaled at a normal flow of $58 \mathrm{l} \cdot \mathrm{min}^{-1}$ and at a slow flow of $36 \mathrm{l} \cdot \mathrm{min}^{-1}$.

At the faster flow, a mean \pm SD $27.7 \pm 9.5 \%$ of the metered dose was deposited in the lung and at the slower flow $14.8 \pm 3.3 \%$ was deposited $(p<0.001)$. Mean lung deposition of terbutaline sulphate inhaled at $57 \mathrm{l} \cdot \mathrm{min}^{-1}$ was $27.0 \pm 7.7 \%$.

We conclude that inspiratory flow has an important effect on lung deposition, but water solubility appears to have no effect.

Eur Respir J., 1994, 7, 69-73.
*Astra Draco AB, P.O. Box 34, S-221 00 Lund, Sweden. **Novecon Research AB, S22370 Lund, Sweden. +Dept of Thoracic Medicine, Royal Free Hospital and School of Medicine, London, UK.

Correspondence: L. Borgström

Human Pharmacology

Astra Draco AB

P.O. Box 34

S-221 00 Lund

Sweden

Keywords: Aerosol deposition

asthma

budesonide

powder inhaler

terbutaline sulphate

Received: December 41992

Accepted after revision July 201993
Inhalation therapy is commonly used in the treatment of asthma, as it results in a high concentration of active drug at the site of action. Local administration requires much lower doses, and greatly reduces the risk of undesirable side-effects. During inhalation, a portion of the dose is, nevertheless, deposited in the oropharynx, and is eventually swallowed. This portion may be systemically absorbed from the gastrointestinal tract and contribute to the overall systemic drug concentration $[1,2]$.

Among the inhalation devices currently on the market, powder inhalers are the most convenient alternative to pressurized metered dose inhalers [3-5]. Turbuhaler ${ }^{\circledR}$ (Astra Draco $\mathrm{AB}$ ), an inspiratory flow-driven, multi-dose, powder inhaler, was originally developed for administering terbutaline sulphate, a $\beta_{2}$-agonist. The glucocorticosteroid budesonide is now also available via Turbuhaler®.

The degree of lung deposition of an inhaled drug is influenced by several factors; an important one being the inhalation manoeuvre [6]. Other possible factors influencing lung deposition related to the properties of the formulation are drug particle size and hygroscopicity [7]. Neither budesonide nor terbutaline sulphate is hygroscopic. It may be assumed, however, that because budesonide is only slightly water soluble $\left(0.014 \mathrm{mg} \cdot \mathrm{ml}^{-1}\right)$, it could be deposited within the humid respiratory tract differently to terbutaline sulphate, a highly water soluble compound $\left(250 \mathrm{mg} \cdot \mathrm{ml}^{-1}\right)$.

In previous studies, lung deposition of terbutaline sulphate, with a peak inspiratory flow of about $60 \mathrm{l} \cdot \mathrm{min}^{-1}$ through Turbuhaler ${ }^{\circledR}$, has been around $20 \%$ of a metered dose $[6,8,9]$. Budesonide has previously been studied by using a nonradioactive method, with inhalation via Turbuhaler ${ }^{\circledR}$ at about $60 \mathrm{l} \cdot \mathrm{min}^{-1}$ and concomitant oral dosing of active charcoal, to prevent absorption of budesonide from the gastrointestinal tract. Lung deposition was determined to be $32 \%$ of a metered dose $[2,10]$. In the present study, performed in a group of healthy volunteers, and using a radioactive method, the objective was to measure lung deposition of budesonide inhaled via Turbuhaler® at two different flows, and to compare it to that of terbutaline sulphate.

\section{Subjects}

Five men and five women participated in the study. Mean age was 32 yrs (range 27-49 yrs), and mean body weight was $66 \mathrm{~kg}$ (range 50-82 kg). Forced expiratory volume in one second $\left(\mathrm{FEV}_{1}\right)$ ranged from $83-127 \%$ of predicted. Before inclusion, the volunteers were considered healthy by a physician, based on a physical examination and haematological and biochemical tests. The study was approved by the Ethics Practices Sub-Committee of the Royal Free Hospital, London, UK, and by the Administration of Radioactive Substances Advisory Committee of the Department of Health in the UK, and was performed in accordance with the guidelines of the Declaration of Helsinki. Informed written consent was obtained from all volunteers before starting the study. 


\section{Methods}

\section{Radiolabelling techniques}

Budesonide and terbutaline sulphate micronized powders were obtained in bulk from Astra Draco AB (Lund, Sweden) and labelled with the radionuclide ${ }^{99 \mathrm{~m} T c}$ at the Royal Free Hospital (London, UK). The radiotracer technique described by NeWMAN et al. [11] was used to label terbutaline sulphate, and budesonide was labelled using an analogous method [12]. Briefly, ${ }^{99 \mathrm{~m} T c}$ was eluted out of the aqueous phase by

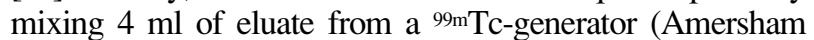
International) with an equal volume of methyl-ethyl-ketone (butanone). The organic phase, containing approximately half of the original activity, was transferred to a glass vessel and subsequently evaporated to dryness. The ${ }^{99 \mathrm{~m} T c}$ was redissolved in $2 \mathrm{ml}$ of distilled water, and then mixed with $50 \mathrm{mg}$ of budesonide powder in a glass beaker. Finally, the water was evaporated in a freeze-drier. The resulting powder of $99 \mathrm{~m} T \mathrm{Tc}-$ budesonide particles was inserted into an empty Turbuhaler®. A mouthpiece was attached, and the inhaler was primed by extracting 10 doses onto a filter using a vacuum pump.

\section{In vitro studies}

The relative distribution of unlabelled budesonide, labelled budesonide and radiolabel was examined using a multistage liquid impinger [11]. The measurements were performed at $60 l \cdot \mathrm{min}^{-1}$, and a $90^{\circ}$ bent glass tube was used as inlet. The size range of the particles delivered to the impinger at the different stages was: stage 1: $>10 \mu \mathrm{m}$; stage 2: $6-10 \mu \mathrm{m}$; stage 3: $3-6 \mu \mathrm{m}$; stage $4:<3 \mu \mathrm{m}$.

\section{In vivo deposition study}

The study was an open, cross-over design involving singledose administrations of $99 \mathrm{mTc}$-budesonide, $0.8 \mathrm{mg}$ (four inhala-

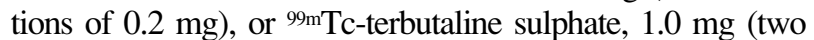
inhalations of $0.5 \mathrm{mg}$ ). Each subject made three separate clinic visits at least six days apart. Each visit involved one of three randomized treatments: budesonide at a peak inspiratory flow (PIF) of $60 l \cdot \mathrm{min}^{-1}$ (BUD60), budesonide at a PIF of $35 \mathrm{l} \cdot \mathrm{min}^{-1}$ (BUD35), and terbutaline sulphate at a PIF of 60 $l \cdot \mathrm{min}^{-1}$ (TBS60). Spirometric lung function $-\mathrm{FEV}_{1}$, peak expiratory flow and maximal mid-expiratory flow - was measured just before drug administration, using a Vitalograph Compact spirometer (Vitalograph Ltd, UK) on each study day. PIF, inhaled volume and breathholding time were controlled during inhalation by means of a Vitalograph Compact, modified to measure inhalation flows. The inhaler was connected in series with the spirometer, and the subjects were instructed to watch the trace on the screen of the Vitalograph Compact and "target breathe" at a specific flow. PIF was required to be within the range $50-70 l \cdot \mathrm{min}^{-1}$ when the target flow was $60 l \cdot \mathrm{min}^{-1}$, and within $30-40 \mathrm{l} \cdot \mathrm{min}^{-1}$ when the target flow was $35 l \cdot \mathrm{min}^{-1}$. Peak flows had to be reached within one second of commencing inhalation. Subjects were requested to hold their breath for $10 \mathrm{~s}$ after inhaling, and then to exhale through a filter (Pall Ultipor, UK), in order to trap exhaled particles. For each subject, recorded inhalation variables were calculated as the mean of four consecutive inhalations on the days budesonide was administered. On the terbutaline sulphate day, values were calculated as the mean of two consecutive inhalations.

Immediately following inhalation, a posterior-anterior view of the chest and stomach and a lateral view of the oropharynx was obtained using an Ohio Nuclear 110 gamma camera, connected on-line to a Nuclear Diagnostic data processing system. Counts were corrected for attenuation by body tissue, in order to estimate deposited radioactivity. Quantities of aerosol present in the mouthpiece and on the exhalation filter were determined by comparing radioactivity of these items with that of a calibration dose drawn onto a second filter by a vacuum pump at about $60 \mathrm{l} \cdot \mathrm{min}^{-1}$ through Turbuhaler $\AA$, and the mouthpiece of that Turbuhaler ${ }^{\circledR}$. Aerosol not recovered in the mouthpiece or on the exhalation filter was assumed to be delivered to the volunteer, and was divided into lung and oropharyngeal fractions according to the corrected counts recorded at each site.

On one of the study days, subjects inhaled $81 \mathrm{mKr}$ gas from a generator. The $20 \%$ contour of the posterior-anterior ventilation scan was taken to define the lung edges, and was used to divide deposition into central, intermediate and peripheral zones in the aerosol scans [11].

\section{Results}

The particle size distributions of budesonide before it went through the labelling procedure (unlabelled), when

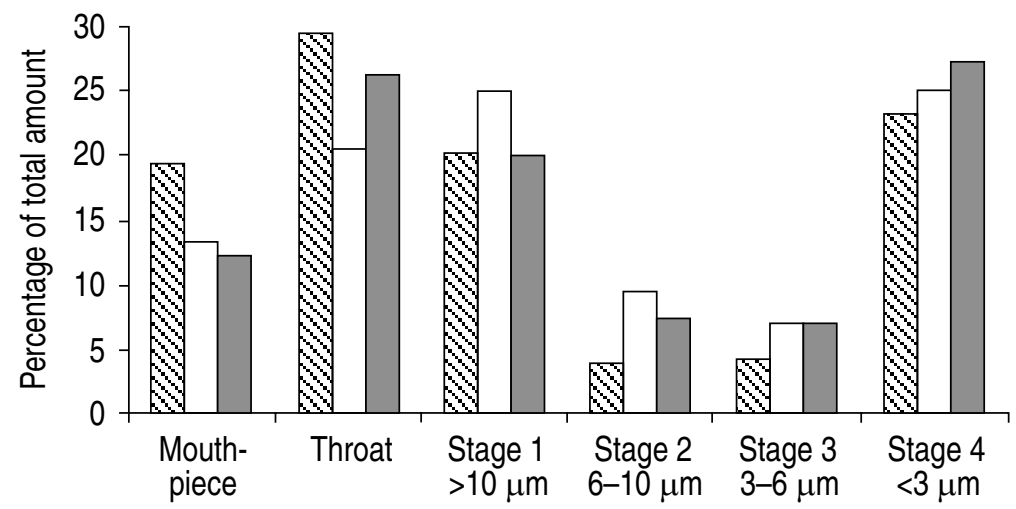

Fig. 1. - Percentage of unlabelled budesonide ( $₫)$ labelled budesonide $(\square)$ and radiolabel ( $\square$ ) from Turbuhaler® in the mouthpiece, throat and the four stages of multistage liquid impinger. 
Table. 1. - Deposition of $99 \mathrm{mTc}$-budesonide (Bud) and $99 \mathrm{mTc}$-terbutaline sulphate (TBS) at various sites after inhalation via Turbuhaler $®$ at flows of about 60 and $35 l \cdot \mathrm{min}^{-1}$

\begin{tabular}{|c|c|c|c|c|c|c|c|c|c|c|c|c|}
\hline \multirow[b]{2}{*}{$\begin{array}{c}\text { Subject } \\
\text { No. }\end{array}$} & \multicolumn{3}{|c|}{ Lung } & \multicolumn{3}{|c|}{ Oropharnyx } & \multicolumn{3}{|c|}{ Mouthpiece } & \multicolumn{3}{|c|}{ Exhaled } \\
\hline & Bud60 & Bud35 & TBS60 & Bud60 & Bud35 & TBS60 & Bud60 & Bud35 & TBS60 & Bud60 & Bud35 & TBS60 \\
\hline 1 & 41.5 & 14.3 & 30.5 & 41.9 & 70.6 & 53.5 & 15.1 & 14.8 & 15.8 & 1.6 & 0.3 & 0.2 \\
\hline 2 & 27.9 & 12.4 & 14.3 & 51.9 & 57.6 & 63.0 & 19.6 & 29.5 & 22.4 & 0.6 & 0.5 & 0.4 \\
\hline 3 & 41.3 & 19.0 & 25.7 & 46.7 & 60.1 & 45.0 & 11.5 & 20.7 & 29.3 & 0.5 & 0.2 & 0.0 \\
\hline 4 & 15.4 & 10.8 & 18.8 & 74.2 & 70.1 & 63.0 & 9.4 & 18.0 & 17.1 & 1.1 & 1.0 & 1.1 \\
\hline 5 & 25.3 & 13.2 & 31.9 & 65.6 & 76.6 & 50.3 & 8.9 & 9.6 & 17.1 & 0.2 & 0.6 & 0.6 \\
\hline 6 & 17.5 & 9.9 & 21.7 & 74.9 & 79.7 & 61.1 & 6.9 & 9.8 & 16.6 & 0.7 & 0.6 & 0.6 \\
\hline 7 & 35.3 & 17.7 & 21.4 & 48.5 & 66.0 & 64.3 & 14.9 & 15.8 & 13.5 & 1.4 & 0.4 & 0.8 \\
\hline 8 & 31.2 & 15.5 & 33.6 & 40.5 & 69.1 & 45.6 & 26.7 & 15.0 & 20.5 & 1.6 & 0.4 & 0.2 \\
\hline 9 & 18.9 & 16.6 & 36.9 & 70.1 & 58.2 & 35.4 & 10.9 & 25.0 & 26.9 & 0.2 & 0.1 & 0.8 \\
\hline 10 & 22.5 & 18.9 & 34.9 & 65.2 & 58.1 & 51.7 & 11.2 & 22.3 & 13.3 & 1.2 & 0.6 & 0.1 \\
\hline Mean & 27.7 & 14.8 & 27.0 & 57.9 & 66.6 & 53.3 & 13.5 & 18.1 & 19.2 & 0.9 & 0.5 & 0.5 \\
\hline SD & 9.5 & 3.3 & 7.7 & 13.4 & 8.0 & 9.6 & 5.9 & 6.4 & 5.4 & 0.5 & 0.4 & 0.3 \\
\hline
\end{tabular}

The fractions are expressed as percentage of metered dose.

taken through the labelling procedure (labelled), as well as the radiolabel, are given in figure 1 . Particles trapped in the third and fourth stages of the impinger (particles $<6 \mu \mathrm{m}$ ) constituted the "respirable" fraction. In this study, respirable fractions of unlabelled budesonide, labelled budesonide and radiolabel were $27.3,31.9$ and $34.1 \%$, respectively.

Lung function on a single study day did not deviate more than $15 \%$ from mean of the three study days. When budesonide was inhaled at targeted PIF of 60 and $35 \mathrm{l} \cdot \mathrm{min}^{-1}$, the mean recorded flows were 58 (range 53-64) and 36 (32-38) $l \cdot \mathrm{min}^{-1}$, respectively. When terbutaline sulphate was inhaled at a targeted PIF of $60 \mathrm{l} \cdot \mathrm{min}^{-1}$, a mean flow of 57 (52-61) $l \cdot \mathrm{min}^{-1}$ was recorded. Time to reach peak flow was in all cases less or equal to one second. Inhaled volume was $2.90 l(2.07-4.97 l)$ for BUD60, $2.54 l(1.36-3.72$ $l$ ) for BUD35 and $2.95 l$ (range 1.97-4.09 $l$ ) for TBS60. Breathholding time was always longer than $8 \mathrm{~s}$. The values of these three parameters did not differ significantly at any time during study days.

Table 2. - Ratio of peripheral to central deposition in lung of $99 \mathrm{mTc}$-budesonide (Bud) and 99mTc-terbutaline sulphate (TBS) inhaled at flows of about 60 and 35 $l \cdot \mathrm{min}^{-1}$

\begin{tabular}{cccc}
\hline & \multicolumn{3}{c}{ Treatment } \\
\cline { 2 - 4 } $\begin{array}{c}\text { Subject } \\
\text { No. }\end{array}$ & Bud60 & Bud35 & TBS60 \\
\hline 1 & 1.86 & 2.56 & 2.59 \\
2 & 2.06 & 2.44 & 2.51 \\
3 & 2.68 & 1.82 & 2.59 \\
4 & 1.47 & 2.25 & 2.39 \\
5 & 1.43 & 2.17 & 1.91 \\
6 & 2.02 & 2.24 & 1.95 \\
7 & 1.44 & 1.33 & 1.69 \\
8 & 1.42 & 1.62 & 1.94 \\
9 & 1.13 & 0.87 & 1.48 \\
10 & 1.73 & 0.87 & 1.21 \\
\hline Mean & 1.72 & 1.82 & 2.03 \\
SD & 0.45 & 0.62 & 0.48 \\
\hline
\end{tabular}

The percentages of the metered dose deposited in the lungs, the oropharynx, and the mouthpiece, as well as that exhaled, are shown in table 1. Inhalation of budesonide at the faster flow resulted in a significant increase in lung deposition compared with the slower flow $(\mathrm{p}<0.001$, paired t-test), which was matched by a decrease in deposition in the oropharynx and mouthpiece. There was no difference in lung deposition between budesonide and terbutaline sulphate when inhaled at $60 \mathrm{l} \cdot \mathrm{min}^{-1}$. The largest fraction of the dose was deposited in the oropharynx in all three cases.

Regional distribution was calculated as the fraction of dose deposited in the peripheral zone relative to that in the central zone. These ratios of peripheral to central zone deposition are shown in table 2. The statistical analysis of budesonide and terbutaline sulphate inhaled at the faster flow did not reveal any significant difference $(p=0.052$, paired t-test).

\section{Discussion}

The influence of PIF on drug delivery via Turbuhaler ${ }^{\circledR}$ has been investigated in this study. In two recent studies carried out in 200 asthmatic adults, mean PIF was around 60 $l \cdot \mathrm{min}^{-1}$, and only six patients failed to generate a PIF of at least $30 l \cdot \mathrm{min}^{-1}$ through Turbuhaler ${ }^{\circledR}[13,14]$. Since PIF of more than $60 \mathrm{l} \cdot \mathrm{min}^{-1}$ does not seem to contribute to an increase in total lung deposition of terbutaline sulphate (unpublished observation), target PIF of 60 and $35 \mathrm{l} \cdot \mathrm{min}^{-1}$ were chosen, in order to represent clinically relevant fast and slow flows through Turbuhaler®. In this study, budesonide was inhaled at 58 and $36 l \cdot \mathrm{min}^{-1}$. At the faster flow $27.7 \%$ of the metered dose was deposited in the lung, and at the slower flow $14.8 \%$. Our results indicate that a direct relationship exists between PIF through Turbuhaler® and lung deposition.

Similar data were recently reported for terbutaline sulphate [6]. In vitro results support the hypothesis that a faster speed through Turbuhaler ${ }^{\circledR}$ facilitates deaggregation of drug particles, reduces particle impaction in the oropharynx, and 
thereby enhances lung deposition [15]. Drug deposition in the lungs at $36 l \cdot \mathrm{min}^{-1}$ is at least as good with Turbuhaler® as with a correctly used pressurized MDI, based on this study and a previous study where Turbuhaler $\AA$ at a PIF of $60 \mathrm{l} \cdot \mathrm{min}^{-1}$ delivered $32 \%$ of budesonide and the pressurized MDI delivered $15 \%$ of a metered dose to the lung [10]. As judged from the efficacy variable, $\mathrm{FEV}_{1}$, asthmatic patients who produced a PIF of $30-40 \mathrm{l} \cdot \mathrm{min}^{-1}$ through Turbuhaler® benefited from treatment by a similar extent to those capable of producing higher flows $[5,16]$. It has also been shown that children above the age of 6 yrs are capable of producing an inhalation flow higher than $30 \mathrm{l} \cdot \mathrm{min}^{-1}$ through Turbuhaler® and, thus, this group should also benefit from budesonide Turbuhaler® [17]. Since lung deposition of budesonide inhaled via Turbuhaler ${ }^{\circledR}$ at a PIF of $60 l \cdot \mathrm{min}^{-1}$ is about twice that from a pressurized MDI, patients who generate flows of about $60 \mathrm{l} \cdot \mathrm{min}^{-1}$ may reduce their prescribed dose of budesonide, without reducing therapeutic efficacy.

Lung deposition of $99 \mathrm{~m}$ Tc-terbutaline sulphate, $0.5 \mathrm{mg}$, via Turbuhaler ${ }^{\circledR}$ at a PIF of about $60 l \cdot \mathrm{min}^{-1}$ through Turbuhaler®, has been assessed in a number of studies. Mean lung deposition determined in this study, $27.0 \%$, is comparable to those reported previously: $16.8,26.9$ and $21.4 \%[6,8,9]$. The low value, $16.8 \%$, in the first study could be explained by a smaller amount of fine particles in the inhaled aerosol, as was discussed by BORGSTRÖM et al. [8].

Other studies on dry powder inhalers have shown lower lung deposition. Thus, values for Spinhaler® have been reported to be $12 \%$ [18], and for Rotahaler ${ }^{\circledR}$ and Diskhaler ${ }^{\circledR}$ values of about $10 \%$ have been reported [19, 20, 21].

Regional deposition can be expressed as the ratio of peripheral to central deposition $(\mathrm{P} / \mathrm{C}$ ratio). Theoretically, a better peripheral deposition might be expected for budesonide than for terbutaline sulphate, because budesonide should absorb less water in the humid airways. The P/C ratios, however, did not significantly differ. If anything, terbutaline sulphate tended to deposit peripherally to a higher extent than budesonide. Thus, the present results indicate that if particle growth does occur, it does not differ between budesonide and terbutaline sulphate, or that it is not a predominant factor influencing peripheral deposition. The $\mathrm{P} / \mathrm{C}$ ratio of budesonide, 1.72, was in the same range as that of the present $\mathrm{P} / \mathrm{C}$ ratio for terbutaline sulphate, 2.03, and previously reported ratios, 2.26 and $1.62[8,9]$. However, further studies are needed to confirm these results, and to sort out the underlying mechanisms for regional deposition.

In this study, the relative amount of radiolabel trapped in the third and fourth stages of the multistage liquid impinger was higher than the relative amount of unlabelled budesonide particles. Thus, if radioactivity is directly related to the relative amount of small, inhaled particles, the degree of lung deposition will be overestimated. For terbutaline sulphate, in vitro data are not available in this study, but previous studies have shown the reverse effect on the particle size distribution [9, 11]. The abnormal particle size distribution is possibly due to an effect exerted on the drug particles by the radiolabel, or by the specific medium used as vehicle for the radiolabel. Different radiolabelling techniques were used for budesonide and terbutaline sulphate: an aqueous medium was used for the lipophilic compound, budesonide, and chloroform for the hydrophilic compound terbutaline sulphate. These diverse findings indicate that the use of radiolabel, to mimic drug, might lead to an overestimate of lung deposition of budesonide, and an underestimate of that of terbutaline sulphate, in comparison with the commercially available Turbuhaler® formulations.

In conclusion, we found that lung deposition of budesonide via Turbuhaler® was directly related to peak inspiratory flow. Differences in water solubility of budesonide and terbutaline sulphate appeared to have little effect on total and regional lung deposition.

\section{References}

1. Newman SP, Pavia D. - Aerosol deposition in man. In: Morén F, Newhouse MT, Dolovich MB, eds. Aerosols in Medicine. Principles, Diagnosis and Therapy. Amsterdam, Elsevier, 1985, pp. 193-217.

2. Borgström L, Nilsson M. - A method for determination of the absolute pulmonary bioavailability of inhaled drugs: terbutaline. Pharm Res 1990; 7: 1068-1070.

3. Crompton GK. - The adult patient's difficulties with inhalers. Lung 1990; (Suppl.): 658-662.

4. Dirksen H, Groth S. - Fenoterol inhalation powder as an alternative to treatment with the metered dose inhaler. Eur J Respir Dis 1983; 64 (Suppl. 130): 48-53.

5. Engel T, Heinig JH, Malling H-J, Scharling B, Nikander K, Madsen F. - Clinical comparison of inhaled budesonide delivered either via pressurized metered dose inhaler or Turbuhaler®. Allergy 1989; 44: 220-225.

6. Newman SP, Morén F, Trofast E, Talaee N, Clarke SW. Terbutaline sulphate Turbuhaler®: effect of inhaled flow rate on drug deposition and efficacy. Int $J$ Pharmaceut 1991; 74: 209-213.

7. Pritchard JN. - Particle growth in the airways and the influence of airflow. In: Newman SP, Morén F, Crompton GK, eds. A new concept in inhalation therapy. Amsterdam, Medicom, 1987; pp. 3-24.

8. Borgström L, Newman SP, Weisz A, Morén F. Pulmonary deposition of inhaled terbutaline: comparison of scanning gamma camera and urinary excretion methods. J Pharm Sci 1992; 81: 753-755.

9. Borgström L, Newman SP. - Total and regional lung deposition of terbutaline sulphate inhaled via a pressurised MDI or via Turbuhaler®. Int J Pharmaceut 1993; 97: 47-53.

10. Thorsson L, Edsbäcker S. - Lung deposition of budesonide from Turbuhaler ${ }^{\circledR}$ is twice that from a pressurised metered dose inhaler (MDI). Thorax 1993; 48: 434.

11. Newman SP, Morén F, Trofast E, Talaee N, Clarke SW. Deposition and clinical efficacy of terbutaline sulphate from Turbuhaler ${ }^{\circledR}$, a new multi-dose powder inhaler. Eur Respir $J$ 1989; 2: 247-252.

12. Thorsson L, Newman SP, Weisz A, Trofast E, Morén F. Nasal distribution of budesonide inhaled via a powder inhaler. Rhinology 1993; 31: 7-10.

13. Engel T, Heinig JH, Madsen F, Nikander K. - Peak inspiratory flow and inspiratory vital capacity of patients with asthma measured with and without a new dry-powder inhaler device (Turbuhaler®). Eur Respir J 1990; 3: 1037-1041.

14. Brown PH, Greening AP, Crompton GK. - Peak inspiratory flow rates in acute asthma: are they adequate for efficient use of a Turbohaler®? Thorax 1992; 47: 239. 
15. Jaegfeldt H, Andersson JAR, Trofast E, Wetterlin KIL. Particle size distribution from different modifications of Turbuhaler®. In: Newman SP, Moren F, Crompton GK, eds. A New Concept in Inhalation Therapy. Amsterdam, Medicom, 1987, pp 90-99.

16. Engel T, Scharling B, Skovsted B, Heinig JH. - Effects, side-effects and plasma concentrations of terbutaline in adult asthmatics after inhaling from a dry-powder inhaler device at different inhalation flows and volumes. Br J Clin Pharmacol 1992; 33: 439-444.

17. Pedersen S, Hansen OR, Fuglsang G. - Influence of inspiratory flow rate upon the effect of a Turbuhaler®. Arch Dis Child 1990; 65: 308-310.

18. Auty RM, Brown K, Neale MG, Snashall PD. - Respiratory tract deposition of sodium cromoglycate is highly dependent upon technique of inhalation using the Spinhaler. Br J Dis Chest 1987; 81: 371-380.

19. Vidgren M, Kärkkäinen A, Karjalainen P, Paronen P, Nuutinen J. - Effect of powder inhaler design on drug deposition in the respiratory tract. Int J Pharmaceut 1988; 42: 211-216.

20. Biddiscombe M, Marriott RJ, Melchor R, Short MD, Spiro SG, Taylor AJ. - The preparation and evaluation of pressurised metered-dose and dry-powder inhalers containing 99mTc-labelled salbutamol. J Aer Med 1991; 4 (suppl 1): 9.

21. Biddiscombe MF, Melchor R, Mak VHF, et al. - The lung deposition of salbutamol, directly labelled with technetium-99m, delivered by pressurised metered dose and dry powder inhalers. Int J Pharmaceut 1993; 91: 111121. 